\title{
Surgery outcomes of lamellar macular eyes with or without lamellar hole-associated epiretinal proliferation: a meta-analysis
}

\author{
Hanyue Xu', Ling Qin², Yifan Zhang ${ }^{1}$, Yinan Xiao ${ }^{1}$ and Ming Zhang ${ }^{2^{*}}$ (D)
}

\begin{abstract}
Background: Given the two different kinds of epiretinal membranes, this study aimed to compare both the structural and functional outcomes of lamellar macular holes with and without lamellar hole-associated epiretinal proliferation (LHEP) after surgery.

Method: Publications up to July 2020 that compared the surgical outcomes of lamellar macular hole with and without LHEP were included. Forest plots were created by using a weighted summary of proportion meta-analysis. Fixed or random effects models were used on the basis of 12 heterogeneity estimates. Meanwhile, to evaluate the stability of the meta-analysis, a sensitivity analysis was carried out.

Results: Eight pertinent publications that contained a total of 176 eyes without LHEP and 173 eyes with LHEP were included. They were all retrospective studies and had a follow-up of at least 6 months. In all studies, the preoperative best corrected visual acuity showed no significant differences between the two groups, and the visual acuity improved in both groups after surgery. The pooled result for the improved best corrected visual acuity was 0.18 (95\% confidence interval $(\mathrm{Cl}), 0.10$ to $0.26 ; P<0.01$ ) between the with and without LHEP groups. The restored ellipsoid zone odds ratio was $0.80(95 \% \mathrm{Cl}, 0.26$ to $2.44 ; P=0.69)$ for the group with LHEP compared to the group without LHEP.
\end{abstract}

Conclusion: Patients without LHEP had better postoperative visual acuity than patients with LHEP. No significant difference in restored ellipsoid zone was found between the two groups.

Keywords: Lamellar macular hole, Lamellar hole-associated epiretinal proliferation, Surgery, Best corrected visual acuity, Ellipsoid zone

\section{Background}

Lamellar macular holes (LMHs), first described in biomicroscopic and angiographic findings by Gass in a case report, is a partial-thickness loss of foveal tissue [1]. The formation of LMHs is attributable to cystoid macular oedema, contraction of the perifoveal epiretinal membrane and vitreous traction [2]. Later, Witkin et al.

\footnotetext{
*Correspondence: mingzhangscu@163.com

${ }^{2}$ Department of Ophthalmology, West China Hospital, Sichuan University, Chengdu No. 37, Guoxue Alley, Chengdu 610041, People's Republic of China Full list of author information is available at the end of the article
}

redefined the LMH diagnosis to include (1) an irregular foveal contour; (2) a break in the inner fovea; (3) an intraretinal split; and (4) intact foveal photoreceptors [2].

The development of ultrahigh-resolution optical coherence tomography (UHR-OCT) has contributed to revealing more microscopic structures of LMHs. UHROCT has allowed visualization of the trapped vitreous or posterior hyaloid, termed epiretinal membranes (ERMs), in most LMH cases. Two types of ERM, tractional ERM (T ERM) and lamellar hole-associated epiretinal proliferation (LHEP), are known as thick ERMs and dense 
ERMs, respectively. Based on the OCT results, T ERM is described as a dense reflective line above the retina, while LHEP is a homogenous medium with much lower reflectivity. Moreover, T ERM has better contractile properties than LHEP [3]. In general, these two kinds of ERM can exist in LMH patients simultaneously or separately, and T ERM is more common than LHEP.

Whether to perform surgery on LMH patients remains controversial. Pars plana vitrectomy with internal limiting membrane (ILM) peeling, the most common surgery among LMH patients, is reportedly useful, particularly for those with significantly low visual acuity [4-6]. However, some patients did not gain better best-corrected visual acuity (BCVA) and even developed full-thickness macular holes (FTMHs) after surgery. Moreover, a previous study reported that some patients could maintain a functionally and morphologically steady state with just observation since the natural progress of the LMH was stable [7].

To determine the differences in prognosis among patients with or without LHEP, some previous studies focused on the surgical outcomes of patients with and without LHEP, but their results were inconsistent. Based on those studies, this meta-analysis aimed to compare both the structural and functional outcomes of patients with and without LHEP after surgery.

\section{Methods}

A comprehensive search for studies that compared surgical outcomes of LMH patients with and without LHEP was carried out in the PubMed, Medline, Embase and Clinical trials databases. The search strategy was "lamellar macular hole" or "LMH" or "epiretinal membrane" or "ERM" or "lamellar hole-associated epiretinal proliferation" or "LHEP" and "surgery" or "operation" or "vitrectomy". All references of the included articles were also screened to guarantee no omission of literature.

\section{Study selection}

For study selection, the inclusion criteria were 1) LMH patients with T ERM or LHEP or both; 2) basic and clinical information of the patients provided; 3) evaluating surgery conducted on the patients; 4) both preoperative and postoperative BCVA reported; and 5) a median follow-up of at least 6 months. The exclusion criteria were as follows: 1) inadequate information on the included patients; 2) only patients who did not undergo surgery were observed; and 3) patients with other ophthalmologic diseases that affect the progress of LMH were included.

\section{Data extraction and validity assessment}

All information from the included studies was separately extracted by two authors with a standardized protocol, including basic characteristics, such as authors, year, cohort size and country; detailed study information, including study design, follow-up period and surgery method; and patient information, including age, sex, and preoperative and postoperative eye-related data. The Newcastle-Ottawa Scale (NOS) was used by two authors to score the quality of all included studies separately, and disagreements were resolved by another author with more experience.

\section{Quantitative data synthesis}

The summary odds ratios (ORs) and 95\% confidence intervals (95\% Cis) for LMH patients with and without LHEP were calculated, and the weighted mean difference (WMD) and $95 \%$ CI was calculated for BCVA. A $P$ value $<0.05$ was considered to be statistically significant. Both fixed effects and random effects models were used to pool the studies. When the $I^{2}$ index, which measures the extent of the heterogeneity, was less than $50 \%$, the conclusions were drawn from the results of the fixed effects model; otherwise, a random effects model was used. To identify potential publication bias, funnel plots were used. Sensitivity analysis was carried out to evaluate the stability of the meta-analysis by omitting one study at a time. All statistical analyses were conducted using Review Manager (version 5.2; Cochrane Collaboration, Oxford, UK; http://ims.cochrane.org/revman) and STATA software (version 11.0; Stata Corp LP, College Station, TX).

\section{Results}

\section{Characteristics of the available studies}

A total of 287 records were obtained using the search method described above (Fig. 1). After removing

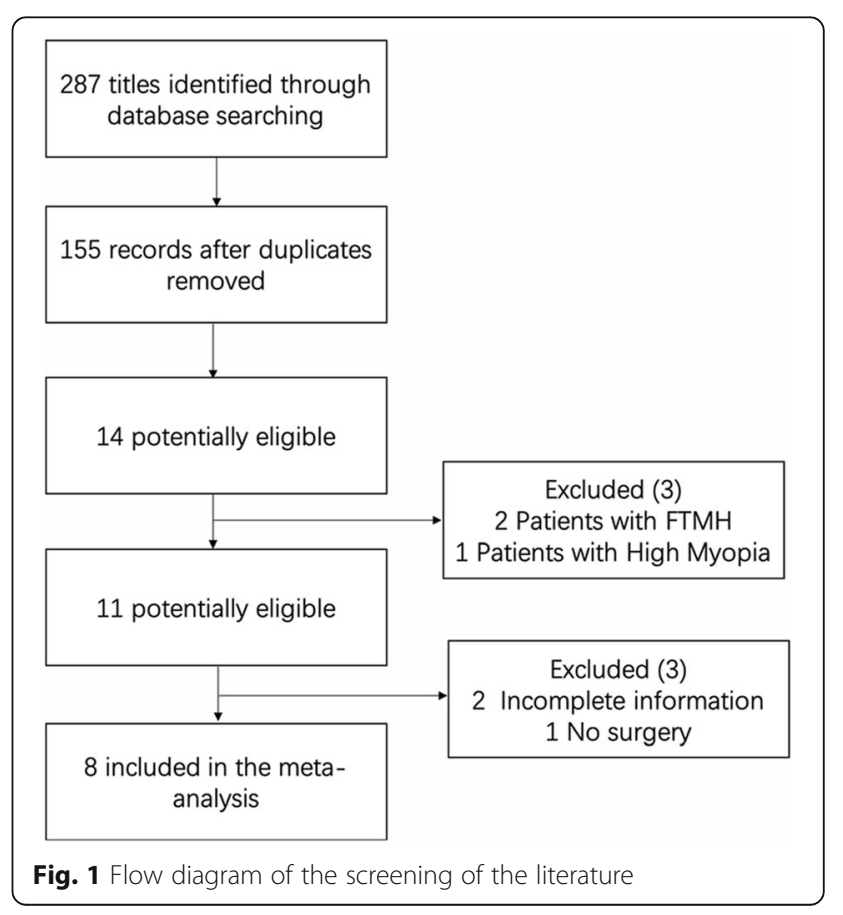


duplications and articles written in other languages, 155 articles remained. By reading the titles and abstracts, 14 papers on LHEP reporting surgical outcomes were identified. Then, the full texts of all articles were read, and 6 of them were discarded because they included patients with FTMH $[8,9]$, recruited LMH patients with high myopia [10], had incomplete information [11, 12] or were an observational study without surgery [3]. Finally, eight studies with 176 eyes without LHEP and 173 eyes with LHEP were included [13-20]. All studies included were retrospective studies, and their detailed information is listed in Tables 1 and 2 .

\section{Outcomes of the meta-analysis}

No significant heterogeneity was observed in the model of BCVA $\left(I^{2}=7 \%, P=0.36\right)$, while heterogeneity existed in the model of restored ellipsoid zone (REZ) $\left(I^{2}=68 \%\right.$,
$P=0.04)$. Therefore, fixed-model analysis was used in the meta-analysis of BCVA, and a random-model was used for REZ. The WMD of the improved logarithm of the BCVA minimum angle of resolution between the with and without LHEP groups was 0.18 (95\% CI, 0.10 to 0.26$)$; the difference was statistically significant $(P<$ 0.001 ). Only three studies reported the status of the ellipsoid zone both before and after surgery. The pooled data revealed an OR of 0.80 ( $95 \% \mathrm{CI}, 0.26$ to 2.44) for REZ, and the difference was not statistically significant at the 95\% CI level $(P=0.69)$ (Fig. 2).

\section{Publication bias and validity assessment}

To assess potential publication bias in the meta-analysis, funnel plots were visually inspected, and no funnel plot asymmetry was visualized (Fig. 3). By Egger's test, no publication bias existed in the studies that reported BCVA $(P=0.543)$. Sensitivity analysis showed that the

Table 1 Demographic characteristics of the included studies

\begin{tabular}{|c|c|c|c|c|c|c|c|c|}
\hline Author & Parolini et al. & Lai et al. & Ko et al. & Choi et al. & Ho et al. & Takahashi et al. & Figueroa et al. & Morescalchi et al. \\
\hline Year & 2011 & 2015 & 2016 & 2017 & 2019 & 2019 & 2019 & 2020 \\
\hline Country & Germany & China & Korea & USA & China & Japan & & Italy \\
\hline $\begin{array}{l}\text { Study } \\
\text { design }\end{array}$ & retrospective & retrospective & retrospective & retrospective & retrospective & retrospective & retrospective & prospective \\
\hline Study period & 2008-2010 & 2009-2013 & 2011-2014 & 2009-2015 & 2013-2016 & 2010-2016 & 2010-2017 & 2015-2017 \\
\hline Surgery & $\begin{array}{l}\text { Vitrectomy } \\
\text { ILM/ERM } \\
\text { peeling }\end{array}$ & $\begin{array}{l}\text { Vitrectomy } \\
\text { ILM/ERM } \\
\text { peeling }\end{array}$ & $\begin{array}{l}\text { Vitrectomy } \\
\text { ILM/ERM } \\
\text { peeling }\end{array}$ & $\begin{array}{l}\text { Vitrectomy } \\
\text { ILM/ERM } \\
\text { peeling }\end{array}$ & $\begin{array}{l}\text { Vitrectomy } \\
\text { ILM/ERM peeling } \\
\text { or LHEP } \\
\text { embedding }\end{array}$ & $\begin{array}{l}\text { Vitrectomy } \\
\text { ILM peeling } \\
\text { LHEP } \\
\text { embedding }\end{array}$ & $\begin{array}{l}\text { Vitrectomy } \\
\text { ILM/ERM } \\
\text { peeling }\end{array}$ & $\begin{array}{l}\text { Vitrectomy } \\
\text { ILM/ERM peeling }\end{array}$ \\
\hline Follow-up & 6 months & $>12$ months & $>6$ months & $>6$ months & $>19$ months & $>12$ months & $>6$ months & 6 months \\
\hline \multicolumn{9}{|l|}{ Without LHEP } \\
\hline Number & 6 & 24 & 58 & 11 & - & - & 77 & - \\
\hline Age $(Y)$ & $67.7 \pm 12.9$ & $59.8 \pm 8.9$ & $64.4 \pm 9.5$ & $68.6 \pm 8.8$ & - & - & $67 \pm 8.9$ & - \\
\hline $\begin{array}{l}\text { Gender } \\
\text { (M/F) }\end{array}$ & $1 / 5$ & $9 / 15$ & $9 / 16$ & - & & & - & \\
\hline FT $(\mu \mathrm{m})$ & - & $146.9 \pm 51.2$ & $154.0 \pm 24.7$ & $166.7 \pm 62.0$ & - & - & $279.1 \pm 108$ & - \\
\hline $\begin{array}{l}\text { DLMHI } \\
(\mu \mathrm{m})\end{array}$ & - & - & $450.4 \pm 201.8$ & $308.2 \pm 121.2$ & - & - & - & - \\
\hline $\mathrm{AL}(\mathrm{mm})$ & - & - & $23.66 \pm 1.59$ & - & - & - & - & - \\
\hline \multicolumn{9}{|l|}{ With LHEP } \\
\hline Number & 13 & 19 & 15 & 11 & 31 & 34 & 26 & 24 \\
\hline Age $(Y)$ & $73.9 \pm 12.9$ & $60.2 \pm 11.2$ & $67.4 \pm 9.5$ & $69.9 \pm 13.6$ & $67.7 \pm 8.7$ & $69.6 \pm 10.1$ & $67 \pm 8.9$ & $72.1 \pm 8.3$ \\
\hline $\begin{array}{l}\text { Gender } \\
\text { (M/F) }\end{array}$ & $8 / 5$ & $9 / 10$ & $4 / 11$ & - & $6 / 25$ & $12 / 22$ & - & $15 / 9$ \\
\hline $\mathrm{FT}(\mu \mathrm{m})$ & - & $98.4 \pm 35.0$ & $116.7 \pm 38.1$ & $96.3 \pm 33.2$ & - & - & $224 \pm 66$ & - \\
\hline $\begin{array}{l}\text { DLMHI } \\
(\mu \mathrm{m})\end{array}$ & - & - & $613.5 \pm 197.3$ & $334.1 \pm 139.8$ & - & - & - & - \\
\hline$A L(m m)$ & - & - & $24.12 \pm 1.84$ & - & - & $\begin{array}{l}24(<26), 10 \\
(26 \leqq)\end{array}$ & - & - \\
\hline
\end{tabular}


Table 2 Ophthalmic information of involved studies

\begin{tabular}{|c|c|c|c|c|c|c|c|c|}
\hline Author & Parolini et al. & Lai et al. & Ko et al. & Choi et al. & Ho et al. & Takahashi et al. & Figueroa et al. & Morescalchi et al \\
\hline \multicolumn{9}{|c|}{ BCVA (pre-operation) } \\
\hline Without LHEP & $0.40 \pm 0.20$ & $0.72 \pm 0.32$ & $0.30 \pm 0.26$ & $0.48 \pm 0.18$ & - & - & $0.38 \pm 0.19$ & - \\
\hline With LHEP & $0.40 \pm 0.20$ & $0.79 \pm 0.37$ & $0.38 \pm 0.38$ & $0.50 \pm 0.25$ & $0.37 \pm 0.27$ & $0.31 \pm 0.25$ & $0.56 \pm 0.19$ & $0.44 \pm 0.16$ \\
\hline \multicolumn{9}{|c|}{ BCVA (post-operation) } \\
\hline Without LHEP & $0.20 \pm 0.30$ & $0.43 \pm 0.44$ & $0.10 \pm 0.10$ & $0.16 \pm 0.16$ & - & - & $0.18 \pm 0.17$ & - \\
\hline With LHEP & $0.20 \pm 0.20$ & $0.45 \pm 0.39$ & $0.33 \pm 0.40$ & $0.40 \pm 0.29$ & $0.17 \pm 0.21$ & $0.10 \pm 0.25$ & $0.39 \pm 0.28$ & $0.17 \pm 0.13$ \\
\hline \multicolumn{9}{|c|}{ EZD (pre-operation) } \\
\hline Without LHEP & - & $9(24)$ & $0(42)$ & $3(11)$ & - & - & $11(77)$ & - \\
\hline With LHEP & - & $13(19)$ & $2(10)$ & $10(11)$ & $10(33)$ & $15(34)$ & $13(26)$ & - \\
\hline \multicolumn{9}{|c|}{ EZD (post-operation) } \\
\hline Without LHEP & - & $8(24)$ & $2(42)$ & $2(11)$ & - & - & $6(77)$ & - \\
\hline With LHEP & - & $7(19)$ & $2(10)$ & $8(11)$ & $4(33)$ & $8(34)$ & $12(26)$ & - \\
\hline \multicolumn{9}{|c|}{ CRT (pre-operation) ( $\mu \mathrm{m})$} \\
\hline Without LHEP & - & - & - & $166.7 \pm 62.0$ & - & - & - & - \\
\hline With LHEP & - & - & - & $96.3 \pm 33.2$ & - & $123.2 \pm 42.6$ & - & $146 \pm 34$ \\
\hline \multicolumn{9}{|c|}{ CRT (post-operation) $(\mu \mathrm{m})$} \\
\hline Without LHEP & - & - & - & $230.6 \pm 103.3$ & - & - & - & - \\
\hline With LHEP & - & - & - & $205.6 \pm 112.9$ & - & $191.2 \pm 45.3$ & - & $272 \pm 24$ \\
\hline
\end{tabular}

Abbreviations: BCVA Best corrected visual acuity, CRT Central Retinal Thickness, EZD Ellipsoid zone destruction, LHEP Lamellar hole-associated epiretinal proliferation

significant findings for BCVA did not change by removing any one of the studies, indicating the stability of this meta-analysis (Fig. 4). According to the NOS results (Supplementary 1), all included studies were high quality with scores equal to or greater than 7 .

\section{Discussion}

Given the different clinical characteristics of LMH patients with ERMs, surgical efficacy remains controversial.
To determine whether surgery is appropriate for all LMH patients, we conducted this meta-analysis. The results suggested that although BCVA improved in all patients after surgery, BCVA in LHEP patients was lower than that in T ERM patients, and the REZ rate was not significantly different between the two groups.

The existence of ERM has been detected for several decades, while its pathogenesis and category remain unclear. T ERM is tractional, and the retinal surface under

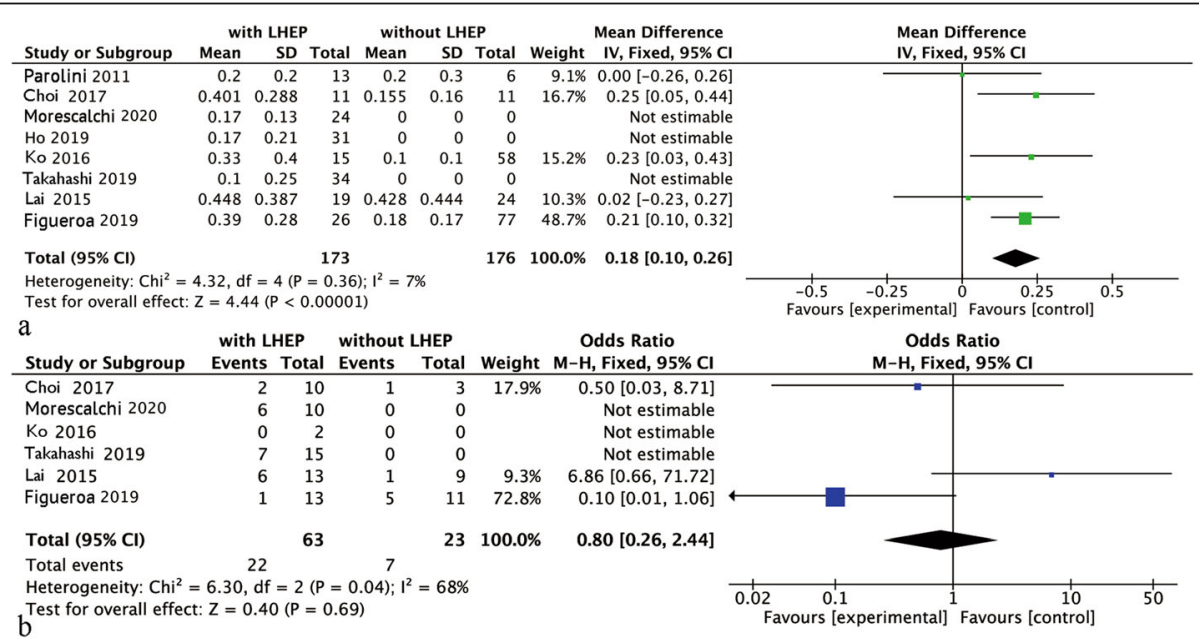

Fig. 2 a Meta-analysis of the best corrected visual acuity in patients comparing eyes with and without lamellar hole-associated epiretinal proliferation (LHEP), b Meta-analysis of the ellipsoid zone restoration rate in patients comparing eyes with and without LHEP 


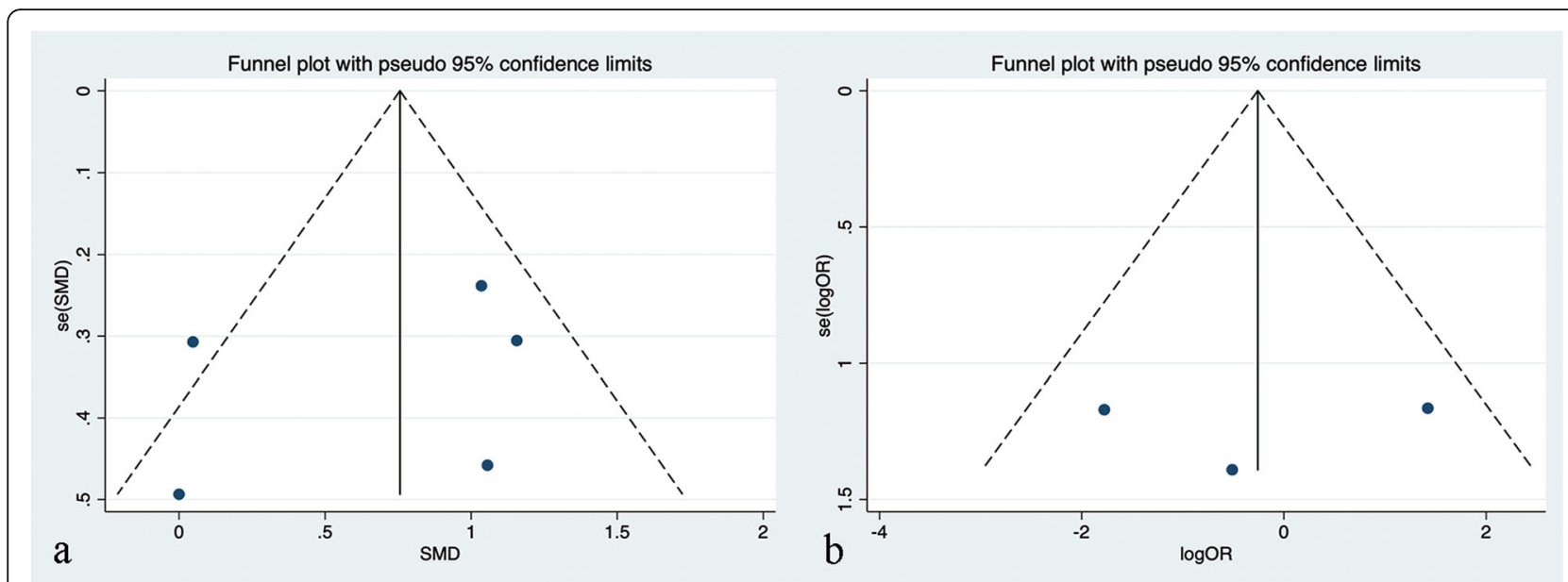

Fig. 3 a The funnel plot of studies included in the analysis of BCVA, $\mathbf{b}$ the funnel plot of studies included in the analysis of ellipsoid zone restoration rate

it is usually plicate. LMH with T ERM always has a short diameter and shallow cleft and is limited to the inner part of the retina; it has been described as resembling a "high hat" by Govetto et al. In contrast, LHEP is an atypical ERM without traction, having a larger and deeper LMH under it [21]. In a previous study, glial cells and hyalocytes were found in both membranes, while $\alpha$ SAM was only found in T ERMs, explaining the tractional ability of T ERMs [22].

The origin of the LHEP is not clear, but there are two main theories. In one theory, as LHEP has abundant clusters of fibrous long-spacing collagen, fibroblasts and hyalocytes, the posterior detachment of the vitreous body might induce both anterior and tangential traction and therefore plays a role in the formation of ERM [16, 22]. However, in another theory, cystic spaces in LHEP formed by leakage of fluid from retinal vessels suggested that LHEP might originate from the middle retinal layers since they share the same characteristics [3]. Proof that the yellow colour of LHEP is xanthophyll mainly produced by muller cells further certifies the relationship between LHEP and the middle retinal layers [23].

Based on the results of the present study, the postoperative BCVA recovery in LHEP patients was less than that in patients without LHEP. In addition, previous studies also indicated that LMH or FTMH eyes with LHEP had worse visual outcomes after surgery $[8,13$, $14,24]$, probably attributable to the more severe destruction of the retina in eyes with LHEP than in those

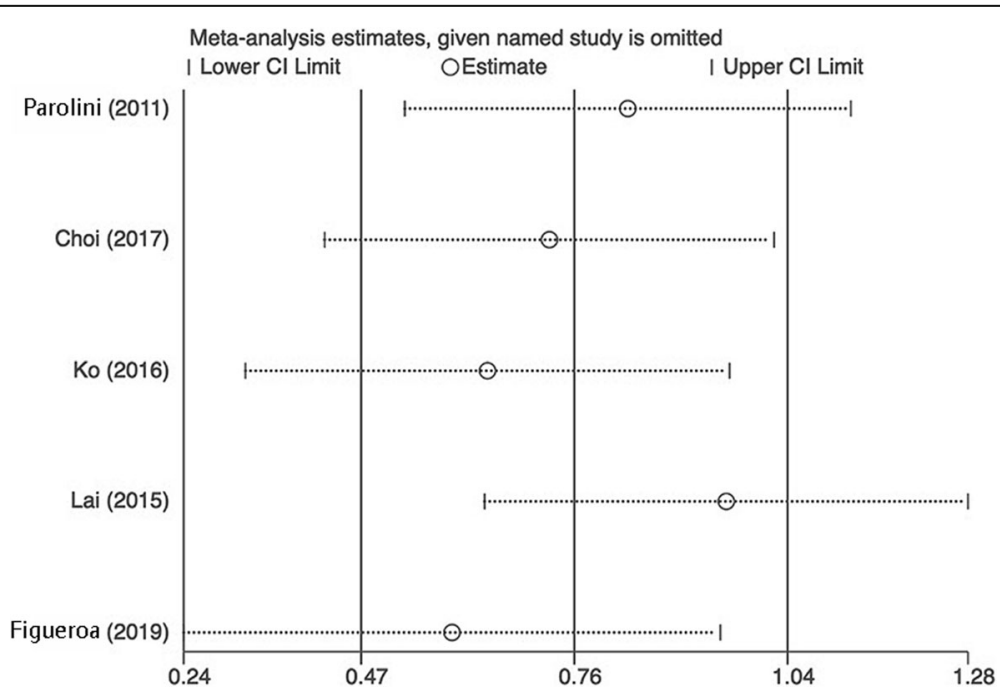

Fig. 4 The sensitivity analysis on the pooled results of the best corrected visual acuity (BCVA) 
without LHEP. However, some studies have reported similar surgery outcomes between eyes with and without LHEP $[10,12,15,16]$. As there have been no significant differences in preoperative BCVA $(<20 / 40)$, surgery method (ILM and ERM peeling) or time of follow-up (>6 months) among these two kinds of studies, more studies with longer follow-up are required to determine the relationship between poor visual outcomes and LHEP. Although many studies have reported a positive association between the REZ and postoperative BVCA $[25,26]$, no significant differences in REZ existed between the with and without LHEP groups in the present study. Previous studies reported that although defection of the ellipsoid zone before surgery was associated with worse postoperative BCVA, its restoration showed no direct association with functional recovery $[5,27]$. Additionally, several influential factors, including the physical conditions of the patients, differing preoperative BCVA, and varying follow-up time, should also be taken into consideration. In a previous study that had a higher REZ rate in LHEP patients, the preoperative BCVA of patients was lower than 20/40 [13], while in the other two studies, the preoperative BCVA had a wider range $[14,15]$.

Patients from six of the eight included studies underwent standard pars plana vitrectomy and conventional ERM and ILM peeling [13-17, 19]. However, the other two studies utilized a new surgical method [18, 20]. Comparing these two surgical methods, the difference between them lies in the disposition of ERM and ILM. Instead of peeling the membrane, the new method double inverted the ERM and flapped the ILM $[28,29]$. This kind of surgery can preserve the LHEP and promote LHM recovery. A previous study indicated that the development of LHEP might be a part of the recovery progress of LMH [15]. This new surgical method and its positive outcomes raise further doubts regarding the necessity of surgery for LHM patients with ERM. Thus, determining whether surgery is necessary for patients with LHEP to obtain functional and morphological restoration requires more study.

However, our study has some limitations. First, the limited number of studies involved inevitably leads to bias, and no subgroup analysis was performed based on the different surgical methods. Thus, more studies are required to obtain more convincing results. Second, only 5 studies reported the number of cataract patients, and the number of patients with combined phacoemulsification and intraocular lens implantation may influence the BCVA outcome. Third, different choices of the gas for the final tamponade, such as air, sulfur hexafluoride, or perfluoropropane gas, may have had a distinct influence on the surgical results.

\section{Conclusion}

This study pooled the postoperative outcomes of LMH patients with and without LHEP and found that the postoperative BCVA of patients without LHEP was better than that of patients with LHEP, and REZ showed no significant difference between the two groups.

\section{Supplementary information}

Supplementary information accompanies this paper at https://doi.org/10. 1186/s12886-020-01617-4

Additional file 1: Supplementary 1. Newcastle-Ottawa quality assessment T scale.

\section{Abbreviations}

BCVA: Best corrected visual acuity; Cl: Confidence interval; ERM: Epiretinal membrane; DLMH: Diameter of lamellar macular hole; FTMH: Full thickness macular hole; ILM: Internal limiting membrane; LHEP: Lamellar holeassociated epiretinal proliferation; LMH: Lamellar macular hole; NOS: Newcastle-Ottawa Scale; OR: Odds ratio; REZ: Restored ellipsoid zone; SFT: Shortest foveal thickness; T ERM: Tractional epiretinal membrane; UHROCT: Ultrahigh-resolution optical coherence tomography; WMD: Weighted mean difference

\section{Acknowledgements}

Not applicable.

\section{Authors' contributions}

$M Z$ and LQ contributed to the study design. HY X and YF Z contributed to the data collection and analysis. HY X and $Y N X$ contributed to the writing of this manuscript. All authors read and approved this manuscript.

\section{Funding}

Not applicable.

\section{Availability of data and materials}

The datasets used and/or analysed during the current study are available from the corresponding author on reasonable request.

Ethics approval and consent to participate

Not applicable.

Consent for publication

Not applicable.

\section{Competing interests}

The authors declare that they have no competing interests.

\section{Author details}

${ }^{1}$ West China School of Medicine, West China Hospital, Sichuan University, Chengdu 610041, People's Republic of China. '2Department of Ophthalmology, West China Hospital, Sichuan University, Chengdu No. 37 , Guoxue Alley, Chengdu 610041, People's Republic of China.

Received: 18 November 2019 Accepted: 18 August 2020

Published online: 25 August 2020

\section{References}

1. Gass JD. Lamellar macular hole: a complication of cystoid macular edema after cataract extraction: a clinicopathologic case report. Trans Am Ophthalmol Soc. 1975;73:231-50.

2. Witkin AJ, Ko TH, Fujimoto JG, Schuman JS, Baumal CR, Rogers AH, Reichel E, Duker JS. Redefining lamellar holes and the vitreomacular interface: an ultrahigh-resolution optical coherence tomography study. Ophthalmology. 2006;113(3):388-97.

3. Pang CE, Spaide RF, Freund KB. Epiretinal proliferation seen in association with lamellar macular holes: a distinct clinical entity. Retina. 2014;34(8): 1513-23. 
4. Sanisoglu H, Elbay A, Sevim S, Celik U, Aktas FB, Durmus E. Surgical therapy versus observation for lamellar macular hole: a retrospective comparison study. Clin Ophthalmol (Auckland, NZ). 2013;7:1843-8.

5. Sun JP, Chen SN, Chuang CC, Lin CW, Lin CJ, Huang JY, Yang CM, Chen MS, Yang $\mathrm{CH}$. Surgical treatment of lamellar macular hole secondary to epiretinal membrane. Graefe's Arch Clin Exp Ophthalmol. 2013;251(12): 2681-8.

6. Michalewska Z, Michalewski J, Odrobina D, Pikulski Z, Cisiecki S, Dziegielewski K, Nawrocki J. Surgical treatment of lamellar macular holes. Graefe's Arch Clin Exp Ophthalmol. 2010;248(10):1395-400.

7. Bottoni F, Deiro AP, Giani A, Orini C, Cigada M, Staurenghi G. The natural history of lamellar macular holes: a spectral domain optical coherence tomography study. Graefe's Arch Clin Exp Ophthalmol. 2013;251(2):467-75.

8. Ubukata Y, Imai H, Otsuka K, Nishizaki M, Hara R, Uenishi M, Azumi A, Nakamura M. The comparison of the surgical outcome for the full-thickness macular hole with/without lamellar hole-associated epiretinal proliferation. J Ophthalmol. 2017;2017:9640756.

9. Lee Kim E, Weiner AJ, Ung C, Roh M, Wang J, Lee IJ, Huang NT, Stem M, Dahrouj M, Eliott D, et al. Characterization of epiretinal proliferation in fullthickness macular holes and effects on surgical outcomes. Ophthalmol Retina. 2019;3(8):694-702.

10. Lai T, Yang CM. Lamellar hole-associated epiretinal proliferation in lamellar macular hole and full-thickness macular hole in high myopia. Retina. 2018; 38(7):1316-23.

11. Marques MF, Rodrigues S, Raimundo M, Costa J, Marques JP, Alfaiate M, Figueira J. Epiretinal proliferations associated with lamellar macular holes: clinical and surgical implications. Ophthalmologica. 2018;240(1):8-13.

12. dell'Omo R, Virgili G, Rizzo S, De Turris S, Coclite G, Giorgio D, dell'Omo E, Costagliola C. Role of lamellar hole-associated epiretinal proliferation in lamellar macular holes. Am J Ophthalmol. 2017;175:16-29.

13. Choi WS, Merlau DJ, Chang S. Vitrectomy for macular disorders associated with lamellar macular hole epiretinal proliferation. Retina. 2018;38(4):664-9.

14. Ko J, Kim GA, Lee SC, Lee J, Koh HJ, Kim SS, Byeon SH, Lee CS. Surgical outcomes of lamellar macular holes with and without lamellar holeassociated epiretinal proliferation. Acta Ophthalmol. 2017;95(3):e221-6.

15. Lai TT, Chen SN, Yang CM. Epiretinal proliferation in lamellar macular holes and full-thickness macular holes: clinical and surgical findings. Graefe's Arch Clin Exp Ophthalmol. 2016;254(4):629-38.

16. Parolini B, Schumann RG, Cereda MG, Haritoglou C, Pertile G. Lamellar macular hole: a clinicopathologic correlation of surgically excised epiretinal membranes. Invest Ophthalmol Vis Sci. 2011;52(12):9074-83.

17. Figueroa MS, Govetto A, Steel DH, Sebag J, Virgili G, Hubschman JP. Pars plana vitrectomy for the treatment of tractional and degenerative lamellar macular holes: functional and anatomical results. Retina. 2019;39(11):2090-8.

18. Ho TC, Ho AY, Chen MS. Reconstructing Foveola by Foveolar internal limiting membrane non-peeling and tissue repositioning for lamellar holerelated epiretinal proliferation. Sci Rep. 2019;9(1):16030.

19. Morescalchi F, Russo A, Gambicorti E, Cancarini A, Scaroni N, Bahja H, Costagliola C, Semeraro F. Peeling of the internal limiting membrane with Foveal sparing for treatment of degenerative lamellar macular hole. Retina. 2020:40(6):1087-93.

20. Takahashi K, Morizane Y, Kimura S, Shiode Y, Doi S, Okanouchi T, Takasu I, Inoue $Y$, Shiraga F. Results of lamellar macular hole-associated epiretinal proliferation embedding technique for the treatment of degenerative lamellar macular hole. Graefe's Arch Clin Exp Ophthalmol. 2019;257(10): 2147-54.

21. Govetto A, Dacquay $Y$, Farajzadeh M, Platner E, Hirabayashi $K$, Hosseini $H$, Schwartz SD, Hubschman JP. Lamellar macular hole: two distinct clinical entities? Am J Ophthalmol. 2016;164:99-109.

22. Compera D, Entchev E, Haritoglou C, Mayer WJ, Hagenau F, Ziada J, Kampik A, Schumann RG. Correlative microscopy of lamellar hole-associated epiretinal proliferation. J Ophthalmol. 2015;2015:450212.

23. Obana A, Sasano H, Okazaki S, Otsuki Y, Seto T, Gohto Y. Evidence of carotenoid in surgically removed lamellar hole-associated epiretinal proliferation. Invest Ophthalmol Vis Sci. 2017;58(12):5157-63.

24. Lee Kim E, Weiner AJ, Ung C, Roh M, Wang J, Lee IJ, Huang NT, Stem M, Dahrouj M, Eliott D, et al. Characterization of epiretinal proliferation in fullthickness macular holes and effects on surgical outcomes. Ophthalmology Retina. 2019;3(8):694-702.

25. Houly JR, Veloso CE, Passos E, Nehemy MB. Quantitative analysis of external limiting membrane, ellipsoid zone and interdigitation zone defects in patients with macular holes. Graefe's Arch Clin Exp Ophthalmol. 2017;255(7): 1297-306.

26. Chan EW, Eldeeb M, Sun V, Thomas D, Omar A, Kapusta MA, Galic IJ, Chen JC. Disorganization of retinal inner layers and ellipsoid zone disruption predict visual outcomes in central retinal vein occlusion. Ophthalmol Retina. 2019;3(1):83-92.

27. Lee CS, Koh HJ, Lim HT, Lee KS, Lee SC. Prognostic factors in vitrectomy for lamellar macular hole assessed by spectral-domain optical coherence tomography. Acta Ophthalmol. 2012;90(8):e597-602.

28. Shiode Y, Morizane Y, Takahashi K, Kimura S, Hosokawa M, Hirano M, Doi S, Toshima S, Hosogi M, Fujiwara A, et al. Embedding of lamellar holeassociated epiretinal proliferation combined with internal limiting membrane inversion for the treatment of lamellar macular hole: a case report. BMC Ophthalmol. 2018;18(1):257

29. Frisina R, Parrozzani R, Pilotto E, Midena E. A double inverted flap surgical technique for the treatment of idiopathic lamellar macular hole associated with atypical epiretinal membrane. Ophthalmologica. 2019;242(1):49-58.

\section{Publisher's Note}

Springer Nature remains neutral with regard to jurisdictional claims in published maps and institutional affiliations.
Ready to submit your research? Choose BMC and benefit from:

- fast, convenient online submission

- thorough peer review by experienced researchers in your field

- rapid publication on acceptance

- support for research data, including large and complex data types

- gold Open Access which fosters wider collaboration and increased citations

- maximum visibility for your research: over $100 \mathrm{M}$ website views per year

At BMC, research is always in progress.

Learn more biomedcentral.com/submissions 